\title{
Üfürüm ile Başvuran Çocukların Ekokardiyografi Sonuçlarının Değerlendirilmesi
}

Evaluation of Echocardiography Results of Children Presenting with Murmur

\author{
Mehmet TÜRE ${ }^{1}(\mathbb{D})$, Alper AKIN ${ }^{1}(\mathbb{D})$, Irfan Kemal KAYA ${ }^{2}(\mathbb{D})$, Şeyhmus YAVUZ ${ }^{2}(\mathbb{D}$ \\ ${ }^{1}$ Dicle Üniversitesi Hastanesi, Çocuk Kardiyoloji Bilim Dalı, Diyarbakır, TÜRKIYE \\ 2 Dicle Üniversitesi Hastanesi, Çocuk Sağlığı ve Hastalıkları Bilim Dalı, Diyarbakır, TÜRKIYE
}

Öz.

Amaç: Çocuk kardiyoloji polikliniğimize kardiyak üfürüm nedeni ile gönderilen hastaların kardiyak üfürüm ve ekokardiyografi bulgularının değerlendirilmesi amaçlanmıştır.

Materyal ve Metod: Hastaların üfürümleri masum ve patolojik olmak üzere ikiye ayrıldı. Hastalara elektrokardiyografik ve ekokardiyografik değerlendirme yapıldı.

Bulgular: Çalışmamıza kardiyak üfürüm nedeni ile başvuran 219 hasta alındı. Hastaların yaş ortalaması 21,61 \pm 34,3 ay idi. Masum üfürümü olan 138 hastada şu an için tedavi gerektirmeyen patent foramen ovale ( 40 hasta), küçük sekundum atriyal septal defekt (1 hasta) saptandı. Patolojik üfürüm olduğu düşünülen hastaların \%96,2'sinde kardiyak patoloji saptanırken, masum üfürüm saptanan hastaların ise hiçbirinde tedavi gereken kardiyak patoloji saptanmadı ( $p<0.01$ ). Üfürümün ekokardiyografik bulguları ayırt etmedeki belirleyiciliği incelendiğinde: Çocuk kardiyoloji hekimleri için fizik muayenenin duyarlıı̆ı̆ı \%66, seçiciliği \%97, pozitif tahmini değeri \%96, negatif tahmini değeri \%83 ve doğruluk oranı \%80 iken, çocuk uzmanlarının duyarlılığı \%57, seçiciliği \%87, pozitif tahmini değeri \%84, negatif tahmini değeri \%64 ve doğruluk oranı $\% 71$ idi.

Sonuç: Çocuk kardiyoloji uzmanları ve çocuk hekimleri arasındaki fizik muayene ile kardiyak patoloji saptama oranı arasındaki fark fizik muayenenin ne kadar önemli olduğunu bir kez daha göstermektedir. Çocuk hekimlerinin kardiyak muayene konusunda çok iyi eğitilmeleri ile ailelere verecekleri sağıklı bilgi sayesinde aileleri ve çocukları gereksiz stresten uzak tutacak ve hastaları hayatlarının ilerleyen dönemlerinde geri dönüşümsüz olabilecek kardiyak patolojilerden korumuş olacaklardır.

Anahtar Kelimeler: Fizik muayene, Kardiyak üfürüm, Çocuk, Ekokardiyografi

\section{Abstract}

Background: We aimed to evaluate the cardiac murmur and echocardiography findings of the patients who were referred to our pediatric cardiology unit for cardiac murmur.

Materials and Methods: The murmurs of the patients were divided into two as innocent and pathological. Electrocardiographic and echocardiographic evaluations were performed on the patients.

Results: 219 patients who applied with murmur were included in our study. The average age of the patients was $21.61 \pm 34.3$ months. Patent foramen ovale ( 40 patients) and small secundum atrial septal defect ( 1 patient) were detected in 138 patients with innocent murmur. While cardiac pathology was detected in $96.2 \%$ of the patients who were thought to have a pathological murmur, no cardiac pathology that required treatment was found in any of the patients with an innocent murmur $(p<0.01)$. When it was aimed to examining the determinacy of murmur in distinguishing echocardiographic findings: The sensitivity of physical examination is $66 \%$ for pediatric cardiology physicians and its specificity is $97 \%$, its positive predictive value is $96 \%$, its negative predictive value is $83 \%$, and the accuracy rate is $80 \%$, The sensitivity of physical examination is $57 \%$ for general pediatricians and its selectivity is $87 \%$. The positive predictive value was $84 \%$, the negative predictive value was $64 \%$, and the accuracy rate was $71 \%$.

Conclusion: The higher rate of detecting cardiac pathologies by physical examination of pediatric cardiologists than pediatricians shows the importance of cardiovascular examination. If general pediatricians receive a good cardiovascular examination training, they will both keep the patient and the family away from unnecessary stress and protect the patients from cardiac pathologies that may be irreversible later in their lives.

Key Words: Child, Physical examination, Cardiac murmur, Echocardiography
Sorumlu Yazar/Corresponding Author

Dr. Mehmet TÜRE

Dicle Üniversitesi Hastanesi, Çocuk

Kardiyoloji Bilim Dalı, Diyarbakır, TÜRKIYE

E-mail: drture21@gmail.com

Geliş tarihi / Received: 04.06.2021

Kabul tarihi / Accepted: 01.07.2021

DOI: $10.35440 /$ hutfd. 948164 


\section{Giriş}

Çocuk hekimleri, üfürüm dışında kardiyak semptomları olmayan çocukları ne zaman çocuk kardiyoloji hekimlerine sevk etmeleri konusunda sorun yaşayabilmektedirler. Bu nedenle çocuk hekimlerinin masum ve patolojik üfürüm ayrımını yapmaları büyük önem taşımaktadır. Çocuklarda kardiyak hastalıkların önemli bir kısmı erken dönemde belirti vermeyebilir. Çocuklarda saptanan üfürümler tüm dünyada çocuk kardiyoloji polikliniklerine yapılan sevklerin en sık sebebidir (1). Fizik muayene ile duyulan kardiyak üfürümler masum veya patolojik olabilir. Masum üfürümler; kalbin boşluklarında veya iki damar arasında genişliği farklı olan bölgeler nedeniyle kanın artmış akım hızı ve oluşan doku titreşimleri sonucunda gelişmektedir (2). Bu nedenle masum ve patolojik üfürüm ayrımı çok önemlidir. Yapılan bir çalışmada masum üfürümün yedi özelliği tanımlanmıştır (3). Bu çalışmada masum üfürümler; soluk alıp vermekle ve pozisyonla karakter değiştiren, sistolik karakterde, kısa süreli, tek, yumuşak, yayılımı olmayan müzikal sesler olarak tanımlanmıştır. Masum üfürümler, çocuklarda \%50-90 oranında, genç yetişkinlerde ise \%15-44 oranında görülmektedir. Konjenital kalp hastalığı görülme oranı ise \%0,5-0,8 arasındadır. Masum üfürümler ateş, kansızlık, tirotoksikoz gibi kalp debisinin arttığı durumlarda herhangi bir kardiyak patoloji olmadan kanın artmış akım hızına bağlı gelişir (4). Kardiyak üfürümler genel olarak masum karakterde olmasına rağmen konjenital veya edinsel kalp hastalığının tek bulgusu olabilir. Elektrokardiyografi (EKG) ve telekardiyografinin üfürümü olan hastalarda kardiyak patolojiyi belirleme açısından yararı sınırlı iken ekokardiyografi (EKO) konjenital veya edinsel kalp hastalıklarında tanı amacıyla kullanılır ve kardiyak patolojilerin değerlendirilmesinde kullanılan en güvenilir ve invaziv olmayan yöntemdir (5). Üfürüm saptanan çocukların ayrıntılı öykü ve kardiyovasküler sistem muayenesi ile değerlendirilmesi gerekir. Çocuk hekimleri masum ve patolojik üfürümleri ayırt edebilirlerse gereksiz acil sevkleri, maddi ve zaman kaybını engelleyebilirler (6). Bu nedenle çocuk hekimlerinin asistanlığı süresince kardiyak muayene eğitimini uygun bir şekilde almaları çok önemlidir.

\section{Materyal ve Metod}

Hastanemizin çocuk kardiyoloji polikliniğine Mart 2019 ile Mart 2021 tarihleri arasında kardiyak üfürüm nedeni ile gönderilen 219 hastanın sonuçları retrospektif olarak incelendi. Çalışma Dicle Üniversitesi Tıp Fakültesi Girişimsel Olmayan Klinik Araştırmalar Etik Kurulu tarafından (22/04/2021 tarih ve 246 sayılı karar) onaylandı ve Helsinki Bildirgesi uyarınca yapıldı. Daha önce kardiyak hastalık ve ek hastalık öyküsü olan hastalar çalışmaya alınmadı. Çalışmaya alınan hastalar; <1 Ay, 1-24 Ay, 25-60 Ay, 61-144 Ay ve $>144$ Ay olmak üzere yaşlarına göre beş gruba ayrıldı. Üfürümün yeri, derecesi ve karakteri değerlendirildi. Üfürümler; çocuk hekimleri ve çocuk kardiyoloji hekimlerinin muayene bulgularına göre ayrı ayrı masum ve patolojik üfürüm diye ikiye ayrıldı. Tüm hastalara 12 derivasyonlu,
$25 \mathrm{~mm} / \mathrm{sn}$ hızda ve $10 \mathrm{~mm} / \mathrm{mV}$ kalibrasyon ile EKG çekildi. Hastaların tümü iki boyutlu, M-mode ve renkli doppler ekokardiyografi teknikleri ile değerlendirilerek muayene bulguları ile ekokardiyografi sonuçları karşılaştırıldı.

\section{istatistiksel Analiz}

Çalışmamızda istatistiksel analiz için 'Statistical Package for Social Sciences (SPSS) for Windows v25.0.0' programı kullanıldı. Ölçüsel değişkenler için ortalama, \pm standart sapma (sd), kategorik değerler için ise sayı ve yüzde kullanıldı. Kategorik verilerin analizi için ki kare testi, normal dağılmayan verilerin korelasyon analizinde spearman, normal dağılan verilerin korelasyon analizinde pearson testi kullanıldı. Normal dağılan iki bağımsız grubun karşılaştırılmasında student t testi kullanıldı. Ekokardiyografi sonuçlarına göre saptanan üfürümün tanısal değerini belirlemek için duyarlılık, seçicilik, pozitif ve negatif tahmini değerler hesaplandı. Yapılan testlerde $p<0,05$ değerleri istatistiksel olarak anlamlı kabul edildi.

\section{Bulgular}

Çalışmamıza kardiyak üfürümü olan 219 hasta alındı. Olguların yaş ortalaması $21,61 \pm 34,3$ ay olarak tespit edildi. Olguların \%51,1'i kız ve \%48,9'u erkek idi. Hastaların yaş dağılımları tablo 1'de görülmektedir.

Tablo 1. Üfürüm saptanan hastaların yaş dağılımları

\begin{tabular}{llc}
\hline Yaş Grupları & Sayı & Yüzde \\
\hline$<\mathbf{A y}$ & 43 & 19,6 \\
$\mathbf{1 - 2 4}$ Ay & 128 & 58,4 \\
$\mathbf{2 5}-60$ Ay & 26 & 11,9 \\
$\mathbf{6 1 - 1 4 4}$ Ay & 19 & 8,7 \\
>144 Ay & 3 & 1,4 \\
\hline
\end{tabular}

Çocuk kardiyoloji uzmanları tarafından saptanan üfürümlerin \%63'ünün masum, \%37'sinin ise patolojik olduğu tespit edildi. Ekokardiyografik incelemede olguların $\% 46,1$ 'inde normal kalp bulguları saptanırken, olguların \%53,9'unda ise farklı patolojik bulgular tespit edildi. En sık tespit edilen bulgular patent foramen ovale (PFO) (\%18,3), ventriküler septal defekt (VSD) $(\% 12,3)$ ve atriyal septal defekt (ASD) $(\% 7,8)$ idi (Tablo 2). Çocuk kardiyoloji uzmanları tarafından yapılan muayenede hastaların \%63'ünde masum üfürüm duyulmasına rağmen ekokardiyografide; PFO, küçük sekundum atriyal septal defekt saptandı. Patolojik üfürüm olduğu düşünülen hastaların \%96,2'sinde kardiyak patoloji saptanırken, masum üfürüm saptanan olguların hiçbirinde tedavi gereken kardiyak patoloji saptanmadı $(p<0.01)$. Üfürüm nedeni ile başvuran hastaların tamamına EKG çekildi. En sık saptanan EKG bulgusu inkomplet sağ dal bloğu (\%14)'idi. Hastaların \%18.3'ünde tespit edilen PFO'nun \%37,5'i yenidoğan dönemindeydi. Hastaların $\% 7,8^{\prime}$ inde tespit edilen ASD'nin tamamı sekundum ASD idi. Hastalarda ekokardiyografi bulgularının, yaş gruplarına göre dağılımı tablo 3'de gösterilmiştir. Muayenesinde masum üfürüm duyulan olguların yaşlarına göre ekokardiyografi bulguları incelendi. 
Tablo 2. Üfürüm saptanan hastaların ekokardiyografi sonuçları

\begin{tabular}{lc}
\hline Tanılar & Hasta sayısı (n) \\
\hline Normal & $101(\% 46,1)$ \\
PFO & $40(\% 18,3)$ \\
ASD & $17(\% 7,8)$ \\
PS & $10(\% 4,6)$ \\
PDA & $13(\% 5,9)$ \\
VSD & $27(\% 12,3)$ \\
AS & $1(\% 0,5)$ \\
FT & $2(\% 0,9)$ \\
ÇÇRV & $1(\% 0,5)$ \\
AVSD & $1(\% 0,5)$ \\
HKMP & $1(\% 0,5)$ \\
SAB & $2(\% 0,9)$ \\
MVP & $3(\% 1,4)$ \\
Toplam & $219(\% 100)$ \\
\hline
\end{tabular}

PFO: Patent foramen ovale, ASD: Atriyal septal defekt, PD: Pulmoner DarIIk, PDA: Patent duktus arteriyozus, VSD: Ventriküler septal defekt, AS: Aort stenozu, FT: Fallot tetralojisi, çÇRV: Çift çıkışlı sağ ventrikül, AVSD: Atriyoventriküler septal defekt, HKMP: Hipertrofik kardiyomiyopati, SAB: Sol ventrikül aberran bant, MVP: Mitral valv prolapsusu

Bu olgulardaki bulgular; tedavi gerektirmeyen PFO ve küçük sekundum ASD idi. Muayenesinde patolojik üfürüm duyulan olguların, ekokardiyografi bulguları incelendiğinde ise, en sık ASD ve VSD olduğu saptandı (Tablo 4). Üfürümün ekokardiyografik bulguları ayırt etmedeki belirleyiciliği incelendiğinde: Çocuk kardiyoloji hekimleri için fizik muayenenin duyarlılığı \%66, seçiciliği \%97, pozitif tahmini değeri \%96, negatif tahmini değeri \%83 ve doğruluk oranı $\% 80$ iken, çocuk uzmanlarının duyarlılığı \%57, seçiciliği $\% 87$, pozitif tahmini değeri \%84, negatif tahmini değeri \%64 ve doğruluk oranı \%71 idi (Tablo 5).

\section{Tartışma}

Çocuklarda doğumsal kalp hastalığı sıklığı \%0,8 oranında görülmektedir (7). Çocuklarda iyi bir kardiyovasküler muayene ile doğumsal kalp hastalıkları belli oranlarda saptanabilir. Kardiyak üfürümlerin doğru tespit edilmesi masum üfürümü olan hastaları kalp hastalığı korkusundan, gereksiz ilaç tedavisinden ve fiziksel aktivite kısıtlamasından korurken, patolojik üfürümü olan hastaları ise hayatlarının ilerleyen dönemlerinde oluşabilecek pulmoner hipertansiyon ve aritmi gibi patolojilerden korur. Patolojik üfürümler, hekimin klinik tecrübesi ve çocuk uyumu gibi sebeplerden dolayı oskültasyon ile atlanabilir (8). Masum ve patolojik üfürüm genellikle klinik değerlendirme ile ayırt edilebilir. Masum ve patolojik üfürümün iyi bir şekilde ayırt edilebilmesi için muayenede uygun ortam sağlanmalı ve muayeneyi yapan hekim tecrübeli olmalıdır (9). Uygun şartlar sağlanamaz ve tecrübeli bir hekim tarafından muayene yapılmaz ise üfürüm duyulmayabilir veya masum ve patolojik üfürüm ayrımı yapılamayabilir. Çocuk kardiyoloji uzmanlarının yaptıkları fizik muayene ile masum ve patolojik üfürümleri yüksek oranda ayırt edebildikleri saptanmıştır (10).
Ancak başka bir çalışmada masum üfürüm olduğunu düşündükleri hastaların ekokardiyografilerinde takip edilmesi gerekebilen kapak yetmezlikleri ve atrial septal defektler saptanmıştır (11). Bu nedenle masum olduğu düşünülen üfürümlerde de EKO incelemesi gerekebileceği vurgulanmıştır.

Yapılan bir çalışmada kardiyak üfürüm nedeni ile başvuran hastaların \%80'inde masum üfürüm saptanmıştır (12). ÇaIışmamızda ise hastaların \%63'ünde masum üfürüm saptandı. Üfürüm ile başvuran hastalarda en sık ASD, PFO ve pulmoner darlık saptanmıştır (8). Başka çalışmada ise PFO sıklığı \%24,9 saptanmış ve PFO saptanan hastaların \%50 civarında yenidoğan hastalardan oluştuğu belirtilmiştir (11). Bizim çalışmamızda ise PFO saptanan hastaların \%37.5'ini yenidoğanlar oluşturmaktaydı. PFO; yenidoğan dönemi için normal bir bulgudur ancak yetişkinlerde; inme, dekompresyon sendromu, migren, vasküler tip baş ağrısı ve obstrüktif tip uyku apnesi ile ilişkilendirilmektedir (13). Tekrarlayan geçici iskemik atak gelişen hastalarda PFO'nun kapatılması gerektiği düşünülmektedir (14). Yenidoğan döneminde iyi bir fizik muayene ile bile kardiyak patolojilerin ancak \%44'nün saptandığı ve bu dönemdeki üfürümün \%54 civarında kardiyak patolojiye bağlı olduğu görülmüştür (15). Yenidoğanlarda rutin muayenenin yapıldığı bir çalışmada sadece fizik muayene ile doğumsal kalp hastalıklarının ancak yarısı tespit edilmiştir. Yenidoğan döneminde sağ kalp basıncı halen yüksek olduğu için sadece fizik muayene ile konjenital kalp hastalığını tanımak çok zordur (16). Yenidoğanlarda üfürüm duyulduğunda hastalar konjenital kalp hastalıkları açısından daha dikkatli şekilde değerlendirilmelidir (17). Yenidoğanlarda üfürüm nedeni ile EKO yapılan bir çalışmada sıklıkla ASD ve VSD saptanmıştır (16). Çalışmamızda da EKO yapılan yenidoğanlarda en sık PFO, ASD ve VSD saptandı. Yenidoğanlarda yapılan başka çalışmada ise yenidoğanların \%92'sinde masum üfürüm saptanmış ancak bu hastaların \%42'sinde ASD, VSD ve pulmoner darlık saptanmıştır (18). Bu çalışmanın sonucunda yenidoğanların kardiyak üfürümlerinin kesin tanısında EKO'nun gerekli olduğu savunulmuştur. Yapılan başka bir çalışmada da yenidoğan döneminde üfürüm saptanmışsa mutlaka ekokardiyografinin yapılması önerilmektedir (19). Çocuklarda on iki yaşından sonra kalp kapak hastalığı sıklığının arttığı bilinmektedir. Özellikle 5 yaşından sonra kapak hastalığının daha sık olduğu saptanmıştır. Kalp kapak hastalığı olan çocuklara operasyonlar öncesi proflaksi verilmezse infektif endokardit gelişebilir (20). Kalp kapak hastalıkları erken tanınıp tedavi edilirse kalp yetmezliğinin gelişmesi önlenebilir. Çalışmamızda literatür ile uyumlu şekilde kalp kapak yetmezliği olan hastaların 7'si beş yaşından büyük iken biri ise 26 aylık idi.

Ekokardiyografinin sık kullanılması nedeni ile kardiyak muayene yeteneğinin azaldığı ve bu nedenle oskültasyon ile üfürüm saptama olasılığının azaldığı savunulmuştur (8). 
Tablo 3. Üfürüm saptanan hastaların yaş gruplarına göre ekokardiyografi bulguları

\begin{tabular}{|c|c|c|c|c|c|}
\hline EKO Tanıları & $<1 \mathrm{Ay}$ & 1-24 Ay & 25-60 Ay & 61-144 Ay & $>144$ Ay \\
\hline PFO & 15 & 21 & 2 & 1 & 1 \\
\hline ASD & 6 & 9 & - & 2 & - \\
\hline PS & 2 & 7 & 1 & - & - \\
\hline PDA & 4 & 9 & - & - & - \\
\hline VSD & 7 & 17 & 3 & - & - \\
\hline AS & - & - & - & - & 1 \\
\hline FT & - & 2 & - & - & - \\
\hline ÇÇRV & - & 1 & - & - & - \\
\hline AVSD & - & 1 & - & - & - \\
\hline HKMP & - & 1 & - & - & - \\
\hline SAB & - & - & - & 2 & - \\
\hline MVP & - & - & 1 & 2 & - \\
\hline MY & - & - & 1 & 2 & 5 \\
\hline
\end{tabular}

EKO: Ekokardiyografi, PFO: Patent foramen ovale, ASD: Atriyal septal defekt, PD: Pulmoner Darlık, PDA: Patent duktus arteriyozus, VSD: Ventriküler septal defekt, AS: Aort stenozu, FT: Fallot tetralojisi, çÇRV: Çift çıkışlı sağ ventrikül, AVSD: Atriyoventriküler septal defekt, HKMP: Hipertrofik kardiyomiyopati, SAB: Sol ventrikül aberran bant, MVP: Mitral valv prolapsusu

Tablo 4. Patolojik üfürüm duyulan hastaların yaş gruplarına göre ekokardiyografi bulguları

\begin{tabular}{|c|c|c|c|c|c|c|c|c|c|c|c|c|}
\hline & PFO & ASD & PS & PDA & VSD & AS & FT & ÇÇRV & AVSD & HKMP & SAB & MVP \\
\hline$<1 \mathrm{Ay}$ & - & 6 & 2 & 4 & 7 & - & - & - & - & - & - & - \\
\hline 1-24 Ay & 1 & 8 & 7 & 9 & 17 & - & 2 & 1 & 1 & 1 & - & - \\
\hline 25-60 Ay & - & - & 1 & - & 3 & - & - & - & - & - & - & 1 \\
\hline 61-144 Ay & - & 2 & - & - & - & - & - & - & - & - & 2 & 2 \\
\hline$>144$ Ay & - & - & - & - & - & 1 & - & - & - & - & - & - \\
\hline
\end{tabular}

PFO: Patent foramen ovale, ASD: Atriyal septal defekt, PD: Pulmoner Darlık, PDA: Patent duktus arteriyozus, VSD: Ventriküler septal defekt, AS: Aort stenozu, FT: Fallot tetralojisi, ÇÇRV: Çift çıkışlı sağ ventrikül, AVSD: Atriyoventriküler septal defekt, HKMP: Hipertrofik kardiyomiyopati, SAB: Sol ventrikül aberran bant, MVP: Mitral valv prolapsusu

Bir çalışmada hafif mitral yetmezlik ve PFO çıkarıldıktan sonra fizik muayenenin ekokardiyografik bulguları ayırt etmedeki duyarlılı̆ı \%31, seçiciliği \%99.2, pozitif tahmini değeri \%92.5, negatif tahmini değeri \%82.2 ve doğruluk oranı \%83 olarak saptanmıştır (11).

Tablo 5. Kardiyak patolojiyi saptamada üfürümün tanısal değeri

\begin{tabular}{lll}
\hline & $\begin{array}{l}\text { Çocuk kardiyoloji } \\
\text { uzmanı }\end{array}$ & $\begin{array}{l}\text { Genel çocuk } \\
\text { uzmanı }\end{array}$ \\
\hline Duyarlılık & $\% 66$ & $\% 57$ \\
Seçicilik & $\% 97$ & $\% 87$ \\
PTD & $\% 96$ & $\% 84$ \\
NTD & $\% 83$ & $\% 64$ \\
Doğruluk & $\% 80$ & $\% 71$ \\
\hline
\end{tabular}

GP: Gerçek pozitif, YN: Yalancı negatif, GN: Gerçek negatif, YP: Yalancı pozitif, PTD: Pozitif tahmini değer, NTD: Negatif tahmini değer.

Bu çalışmada masum üfürüm düşünülen hastalarda ekokardiyografi yapılmazsa PFO ve atrial septal defektler, daha da önemlisi hafif kapak hastalıklarının tanısının gecikebileceği savunulmuştur. Başka bir çalışmada da fizik muayene ile minör kalp patolojilerinin tespitinin zor olduğu savunulmuştur (21). Üfürümler hekimler tarafından masum olarak değerlendirilse bile aile için endişe kaynağı olabileceği belirlenmiştir (22). Bazı çalışmalarda üfürüm nedeni ile hastaneye getirilen çocukların ailelerinin \%80'ninin EKO yapılmasını istedikleri belirlenmiştir $(22,23)$. Ayrıca üfürüm nedeni ile çocukları çocuk kardiyoloji bölümüne sevk eden hekimlerin aileleri EKO için göndermeleri de eklenince hastalara EKO yapmak kaçınılmaz hale gelmektedir $(8,22,23)$. Yapılan bazı çalışmalar çocuk hekimlerinin masum ve patolojik üfürüm ayırımında çocuk kardiyoloji uzmanları kadar iyi olmadığını göstermiştir (24). Çocuk kardiyoloji uzmanı tarafından masum üfürüm saptanan hastalarda kardiyak açıdan başka incelemelere gerek olmadığı savunulmuştur (25). Bu çalışmada çocuk hekimleri ve çocuk kardiyoloji hekimleri arasında fizik muayene ile kardiyak patolojileri saptama açısından anlamlı farklılık saptanmamıştır (sırası ile \%79 ve \%85). Yapılan başka bir çalışmada ise çocuk hekiminin patolojik üfürümü tanımadaki duyarlıı̆ı \%96, masum üfürümleri saptamadaki özgüllüğü \%68 olarak saptanmıştır (26). Başka çalışmada çocuk kardiyoloji hekimlerinin çocuk hekimlerine göre patolojik üfürümü masum üfürümden daha iyi ayırt ettikleri saptanmıştır (27). Çocuk asistanlarının çocuk kardiyoloji bölümünde geçirdikleri süre arttıkça üfürüme doğru tanı koyma oranlarının arttığı saptanmıştır (28). Bizim çalışmamızda da çocuk kardiyoloji hekimlerinin hem masum hem de patolojik üfürümleri genel çocuk hekimine göre daha iyi tespit ettikleri belirlendi. Bu da genel çocuk hekimlerinin pediatri eğitimi sırasında kardiyovasküler muayeneye daha fazla önem vermeleri gerektiğini göstermektedir. Yenidoğan ve erken süt çocukluğu döneminde sadece fizik muayene yapılması masum üfürümleri patolojik üfürümlerden ayırt etmek için yeterli olmayabilir. Daha büyük çocuklarda muayeneyi yapacak hekim kardiyak muayene eğitimini yeterli düzeyde almış ise üfürümleri saptamada fizik muayenin büyük ölçüde yeterli olduğu saptanmıştır. Günümüzde ekokardiyografinin 
çok yaygın kullanılması nedeni ile hekimler kardiyak patolojileri değerlendirmede öykü ve fizik muayeneyi yeterli düzeyde kullanmamaktadırlar. Çocuk hekimleri eğitimleri süresince kardiyak muayeneyi uygun şekilde öğrenirlerse hasta ile karşılaştıklarında iyi bir kardiyovasküler muayene ile hem hasta ve aileyi gereksiz stresten koruyacak hem de hastaları hayatlarının ilerleyen dönemlerinde oluşabilecek geri dönüşümsüz kardiyak patolojilerden korumuş olacaklardır.

Etik onam: Çalışma için Dicle Üniversitesi Tıp Fakültesi Girişimsel Olmayan Klinik Araştırmalar Etik Kurulu tarafından (22/04/2021 tarih ve 246 sayılı karar) etik onam alındı.

\section{Yazar Katkıları:}

Konsept: M.T., A.A., I.K.A., Ş.Y.

Literatür Tarama: M.T., A.A.

Tasarım: A.A., I.K.A., S.Y.

Veri toplama: M.T., A.A., I.K.A., Ş.Y.

Analiz ve yorum: M.T., A.A., Ş.Y.

Makale yazımı: M.T., A.A., I.K.A.

Eleştirel incelenmesi: A.A., i.K.A., Ş.Y.

Çıkar Çatışması: Herhangi bir çıkar çatışmamız bulunmamaktadir.

Finansal Destek: Araştırma kapsamında herhangi bir kurum ya da kuruluştan finansal destek sağlanmamıștır.

\section{Kaynaklar}

1. Ekici F, Ünal S, Dablan S, Alpan N, Çevik BŞ, Vidinlisan S. Yenidoğan yoğun bakım ünitesindeki 119 bebeğin klinik ve ekokardiyografik değerlendirmesi. Türkiye Çocuk Hastalıkları Dergisi 2010;4:22-9.

2. Park MK. Physical examination. Pediatric cardiology for practitioners. 5th ed. St. Louis: Mosby Year Book, 2007: 2337

3. Bronzetti G, Corzani A. The seven "s" murmurs: An alliteration about innocent murmurs in cardiac auscultation. Clin Pediatr (Phila) 2010;49:713.

4. Sapin SO. Recognizing normal heart murmurs. Pediatrics 1997; 99: 616-9

5. Allen HD, Phillips JR, Chan DP. History and physical examination. In: Allen HD, Driscoll DJ, Shaddy RE, Feltes TF (eds). Heart Disease in Infants, Children and Adolescents. Philadelphia: Williams\&Wilkins, 2008:58-66

6. Cassidy SC, Allen HD, Phillips JR. History and physical examination. In: Allen HD, Driscoll DJ, Shaddy RE, Feltes TF (eds). Moss and Adams' Heart Disease in Infants, Children and Adolescents. 8th ed. Philadelphia: Williams\&Wilkins, 2013:82-93.

7. Flanagan MF, Yeager SB, Weindling SN, Avery GB, Fletcher MA, Mc Donald MG (eds). Cardiac disease. In: Neonatology, Pathophysiology \& Management of the newborn. 5th ed. Philadelphia: Lippincott, Williams \& Wilkins, 1999: 57796.

8. Çimen D, Oran B, Arıbaş S, Baysal T. Çocukluk çağındaki masum üfürümlerde ekokardiyografik inceleme yapalım mı? Selçuk Tıp Dergisi 2008;24:131-7

9. 9.Smith KM. The innocent heart murmur in children. J Pediatr Health Care 1997;11:207-14.

10. Mccrindle BW, Shaffer KM, Kan JS, Zahka KG, Rowe SA, Kidd L. Cardinal clinical signs in the differentiation of heart murmurs in children. Arch Pediatr Adolesc Med 1996;150:169-74.

11. Ibrahim İlker ÇETiN, Doğukan AKTAŞ, Mehmet Emre ARI, Abdullah KOCABAŞ, Filiz EKici , Tülin Revide ŞAYLI. Is Echocardiographic Evaluation Necessary for all Children with Cardiac Murmur? Türkiye Çocuk Hast Derg/Turkish J Pediatr Dis / 2015; 3: 189-94

12. Karacan $M$, Olgun $H$, Orhan MF, Altay ND, Öztürk CF, Karakelleoğlu C. Undiagnosed cardiac abnormalities among school-aged children. J Curr Pediatr 2010;8:63-6.

13. Yokuşoğlu $M$, Uzun $M$, Karaeren $H$. Patent foramen ovale tanısı ve güncel tedavi endikasyonları. TGKD 2007;11:2430.

14. Komar M, Podolec P, Przewłocki T, Wilkołek P, Tomkiewicz-Pająk L, Motyl R. Transoesophageal echocardiography can help distinguish between patients with "symptomatic" and "asymptomatic" patent foramen ovale. Kardiol Pol 2012;70:1258-63.

15. Ainsworth SB, Wyllie JP, Wren C. Prevalence and clinical significance of cardiac murmurs in neonates. Arch Dis Child Fetal Neonatal. 1999;80:43-5.

16. Güven $H$, Bakiler AR, Kozan M, Aydınlıoğlu H, Helvacı M, Dorak Ç. Yenidoğan servislerinde doğumsal kalp hastalıkları. Çocuk Sağlığı Hast Derg 2006;49:8-11.

17. Rodriguez CJ, Homma S. Management of patients with stroke and a patent foramen ovale. Curr Cardiol Rep 2004;6:143-6.

18. Şap F, Baysal T, Karataş Z, Altın H, Alp H, Karaarslan S. Yenidoğan döneminde duyulan üfürümün doğuştan kalp hastalığını saptamadaki önemi. Yeni Tıp Derg 2012;29:80-83.

19. Azhar AS, Habib HS. Accuracy of the initial evaluation of heart murmurs in neonates: Do we need an echocardiogram? Pediatr Cardiol 2006; 27: 234-7.

20. Erol MK. Asemptomatik kapak hastasının takip ve tedavisi. Anadolu Kardiyo Derg 2009;9:17-24

21. Alvares $S$, Ferreira $M$, Ferreira $H$, Mota $C R$. Initial assessment of heart murmurs in children: Role of complementary diagnostic tests. Rev Port Cardiol 1997;16:621-4.

22. Mccrindle BW, Shaffer KM, Kan JS, Zahka KG, Rowe SA, Kidd L. An evaluation of parental concerns and misperceptions about heart murmurs. Clin Pediatr 1995; 34:25-34.

23. Aktaş D, Çetin ii, Yıldız J, Arı ME, Eminoğlu S, Ekici F, Kocabaş $A$. Genel muayene sırasında saptanan kardiyak üfürümlerde ailelerin endişe düzeyi ve farkındalığı, çocuk kardiyolojisi uzmanından beklentileri. Türkiye Çocuk Hast Derg 2014;8:59-63.

24. Gaskin PRA, Owans SE, Talner NS, Sanders SP, Li JS. Clinical auscultation skills in pediatric residents. Pediatrics. 2000;105:1184-7.

25. Rajakumar K, Wiesse M, Rosas A, Erdoğan G, Pyles L. Comparative study of clinical evaluation of heart murmurs by general pediatricians and pediatric cardiologist. Clinical Pediatrics. 1999;38:511-8.

26. Hansen LK, Birkebaek NH, Oxhoj H. Initial evaluation of children with heart murmurs by the nonspecialized pediatrican. Eur J Pediatr. 1995;154:15- 7.

27. Tülay KAMAŞAK, Embiya DiLBER. Çocukluk Çağındaki Masum Üfürümlerin Tanısında Fizik Muayene, Elektrokardiyografi, Telekardiyografi ve Ekokardiyografinin Yeri. Online Türk Sağlık Bilimleri Dergisi 2019, Cilt 4, Sayı 3, 360-76

28. Abdullah Kocabaş, Seda Çetinkaya Özer, Fırat Kardelen, 
Halil Ertuğ, Gayaz Akçurin. Evaluation of the Skills of Pediatric Residents in Childhood Cardiac Murmurs. Türkiye Çocuk Hast Derg/Turkish J Pediatr Dis / 2013; 4: 163-7 